\title{
Strain patterns during tensile, compressive and shear fatigue of human cortical bone and implications for bone biomechanics
}

\author{
K. Winwood ${ }^{1}$, P. Zioupos ${ }^{2}$, J.D. Currey ${ }^{3}$, J.R. Cotton ${ }^{4}$, M. Taylor ${ }^{5}$ \\ ${ }^{1}$ Institute for Biophysical \& Clinical Research into Human Movement, Manchester Metropolitan University, \\ Alsager, UK \\ ${ }^{2}$ Department of Materials \& Medical Sciences, Cranfield University Postgraduate Medical School, \\ Shrivenham, $U K$ \\ ${ }^{3}$ Department of Biology, University of York, York, UK \\ ${ }^{4}$ Department of Engineering Science and Mechanics, Virginia Tech, Blacksburg, VA, USA \\ ${ }^{5}$ Bioengineering Science Research Group, School of Engineering Science, University of Southampton, \\ Southampton, UK
}

Correspondence to: K. Winwood, K.Winwood@mmu.ac.uk

Contract grant sponsor: the EPSRC-UK grant number GR/M59167

Running title: strain rates in human cortical bone fatigue

\begin{abstract}
:
It is a common theme in basic bone biomechanics and in biomechanical applications that much of the behaviour can be determined and is dictated by the level of strain, whether this pertains to bone physiology, bone remodelling, osseinduction, osseointegration or the development of damage. The development of damage, demonstrated by stiffness loss measurements, has already been reported in detail in the literature. However, the systematic study of the development of 'plastic' (irrecoverable) strains, which are associated with the inelastic mechanical behaviour of bone tissue has generally been overlooked. The present study compares the rates at which the elastic $\left(\epsilon_{\mathrm{a}}\right)$ and plastic components $\left(\epsilon_{p}\right)$ of strain developed during tensile, compressive, and shear fatigue in human cortical bone of six individuals aged between 53 and $79 \mathrm{yrs}$ of age. The overall hypothesis of this investigation is that there is a common underlying factor in the damage-related behaviour of bone, which may allow us to link together the various aspects of the damage related behaviour of bone. The rate of development of plastic strain $\left(\dot{\epsilon}_{\mathrm{p}}\right)$ and the rate of damage $\left(\dot{\epsilon}_{\mathrm{a}}\right)$ are described as a function of the cycle number, the stress $(\sigma)$, and/or stress normalised by the modulus of elasticity $(\sigma / \mathrm{E})$. The implications of our findings are discussed with respect to simple models/mechanisms, which may underlie the observed behaviour.
\end{abstract}

Key words: elastic- plastic- inelastic strain; cortical bone; fatigue; damage

\section{INTRODUCTION}

It is a common theme in basic bone biomechanics and in biomechanical applications which involve bone physiology and remodelling that much of the behaviour can be determined and is dictated by the level of strain. In orthopaedic implants for instance, the mechanical competence and density of the cancellous bone in contact with the implant ${ }^{1-3}$ will determine through a strain mediated behaviour the chances for loosening and subsidence of the implant ${ }^{4,5}$ and whether a costly revision operation is averted ${ }^{6}$. Age related changes in bone matrix, experienced via either modified stress/strain behaviour, or a strain related bone deposition and bone induction may critically affect the chances for osseointegration. The strain level has also been implicated for the onset of damage in basic bone biomechanics where at a certain strain threshold microcracking ensues and the tissue demonstrates yield ${ }^{7}$. Microcracking damage is associated with inelastic strain behaviour, which 
shows itself in two ways: increasing elastic strain amplitudes and the development of 'plastic' (irrecoverable) strains.

Previous studies have examined the systematic development and accumulation of damage in fatigue in both animal and human tissue ${ }^{8-10}$ and in both cortical and cancellous bone ${ }^{11,12}$. More recently the present authors have reported a similar systematic study of the development of the 'plastic' (irrecoverable) component of strain in human bone from individuals of various ages in fatigue ${ }^{13,14}$ The irrecoverable component of strain has also been shown by these authors (at least in tension) to equal in both effect and nature the creep behaviour of the tissue ${ }^{15}$. Strong associations have also been established between the 'rate of damage' (based on the rate of development of elastic strain amplitude) the 'cycles to failure' and the development of 'irrecoverable strains' during tensile fatigue tests ${ }^{16}$.

However, the way in which the magnitude of the plastic strain $\left(\epsilon_{p}\right)$ and the amplitude of the elastic strain $\left(\epsilon_{\mathrm{a}}\right)$ develop as a function of stress have not yet been fully documented, especially for behaviour pertaining to all 3 main loading modes (including shear which is usually overlooked) and to a possible variability between individuals. The rate of development of plastic strain $\left(\dot{\epsilon}_{\mathrm{p}}=\Delta \epsilon_{\mathrm{p}} / \Delta \mathrm{N}\right)$ and the rate of damage ( $\dot{\epsilon}_{\mathrm{a}}=\Delta \epsilon_{\mathrm{a}} / \Delta \mathrm{N}$, this is practically the rate of 'damage' strain as used by Haddock et al. ${ }^{12}$ ) need to be followed as a function of the cycle number, as a function of function of stress $(\sigma)$ and/or stress normalised by the modulus of elasticity $(\sigma / E)$.

The underlying cause of damage is of course the existence and growth of microcracks. However, the effects these cracks may have on the mechanical behaviour of the tissue may be any of a number that includes the response in terms of strains, the final fracture outcome, the redistribution of stresses and so forth. However, what would be important with respect to the data we are presenting here is if we are able to discern commonalities and easily defined patterns. The present study compares the rates at which the elastic and plastic components of the strain developed during tensile, compressive, and shear fatigue in human cortical bone of six individuals aged between 53 and $79 \mathrm{yrs}$ of age. The overall hypothesis of this investigation is that there is a common underlying factor in the damage-related behaviour of bone, which may allow us to link together the various aspects of the damage related behaviour of bone.

\section{MATERIALS AND METHODS}

Specimens from six donors (five females \& one male) aged between 53 to 79 years were collected, with full ethical approval and relatives' permission and stored at $-20^{\circ} \mathrm{C}$ prior to testing. This tissue was donated after consent for transplantation purposes and therefore, it originated from otherwise healthy individuals with no known reported metabolic bone tissue conditions. Tensile and compressive fatigue specimens were harvested from the diaphysis region in the longitudinal direction and shaped into dumb bell specimens $(30 \mathrm{~mm}$ long, $2 \mathrm{~mm}$ thick, $7 \mathrm{~mm}$ wide at the shoulders, $5 \mathrm{~mm}$ wide over a central $10 \mathrm{~mm}$ gauge length). Shear specimens were cut transversely nearer the metaphyses of the same femurs in flat sections of cortical bone that allowed the preparation of transverse samples to test for shear in between the osteons (Fig. 1) and in a direction where most in-vivo fatigue microcracks have been reported to be confined ${ }^{17,18}$. Shear tests followed the Iosipescu method ${ }^{19}$, an in-plane composite shear test utilizing a notched beam type sample which is loaded so as to produce a zero bending moment across the notch or test section. Samples were $25 \mathrm{~mm}$ long, $5 \mathrm{~mm}$ deep, $3 \mathrm{~mm}$ wide, and a $1 \mathrm{~mm}$ deep 90 v-notch on either side and according to an earlier application for bone ${ }^{20}$. The Iosipescu method allows for the in-plane shear in a homogeneous and uniform deformation moe which can not be achieved by the more usually iemployed torsion test methods.

All specimens were sanded and polished by using carbide papers (grade 800-1200grit) and then polished to a mirror finish by the use of alumina slurry paste (MetPrep Ltd., Coventry, UK, gamma alumina $0.05 \mu \mathrm{m}$ ). Sample preparation was preformed under constant water irrigation, to prevent the production of microcracks or damage to the specimen prior to mechanical testing. Additionally 
specimens were stained in Fuchsin staining agent (Fisher Scientific $\left.{ }^{\circledR}\right)$, to verify that no cracks had been induced by the preparation procedure.

Specimens were fatigue cycled sinusoidally at a frequency of $2 \mathrm{~Hz}$ using a Dartec ${ }^{\circ} \mathrm{HC} 25$ servohydraulic testing machine (Zwick Roell Group Ltd, Southern Avenue, Leominster, Hereford, UK) equipped with a 5kN Sensotec ${ }^{\circledR}$ load cell (2080 Arlingate Lane, Columbus, Ohio, 43228, USA) and with specially fabricated grips for each of the three main loading modes. Tests were carried out at a constant $37^{\circ} \mathrm{C}$ and fully immersed in Ringers physiological solution. Strains were recorded by the use of a waterproof fatigue rated extensometer and data was collected by using Dartec $®$ Toolkit 96 V4.09 software. In each cycle the strain amplitude (at constant stress amplitude), the plastic strain (which is defined as the irrecoverable translation on the strain axis at zero stress), the cycle number, the time and the peak load values (for verification) were recorded as entry rows and passed onto a spreadsheet in real time. Every so often (in practice at cycle numbers that followed a power law of 3 increment, $\mathrm{N}=1,3,9,27 \ldots$ ) the full load extension data was recorded at a sampling frequency of $500 \mathrm{~Hz}$ in order to produce the full load/extension loops at certain points of the fatigue lifetime to demonstrate the qualitative changes in the load/extension behaviour. More details of this set up were presented in ${ }^{14-16}$.

Failure was defined by either the complete rupture of the sample (as in tension), or at the point where the sample could not further sustain the cyclically imposed level of stress and exhibited high levels of strain. In the case of compression and shear some stress will be transferred through the material from one set of grips to the other via a ligament area of crushed tissue. Typical stress/strain cycles are shown in Fig. 2, where also the various components of strain are defined.

Statistics and curve fitting were performed by using either Minitab (v.13, Minitab Inc, State College, PA 16801-3008, USA), Excel (2002-SP3, Microsoft Corp. and SigmaPlot (v.8.02, SPSS Inc. Chicago IL, USA) software.

\section{RESULTS}

The variation of elastic $\left(\epsilon_{\mathrm{a}}\right)$ and plastic strain $\left(\epsilon_{\mathrm{p}}\right)$ as a function of cycle number until failure was examined in all three loading modes (Fig. 3) as in the studies by Winwood et al. ${ }^{13,14}$.

In tension (Fig. 3a) the complete trace of strains vs. cycles shows 3 phases: (I) in the primary phase (between 0 and about $10 \%$ of fatigue lifetime for most samples) the tissue shows strong transient effects and a curvilinear behaviour; (II) in the secondary phase, which stretched usually in between $10-90 \%$ of lifetime, the behaviour is reasonably linear; (III) in the tertiary region (over $90 \%$ of lifetime) near failure the increase in strain was rapid and unpredictable. The situation was slightly different for compression (Fig. 3b) and shear due to the absence of a primary phase and the nonlinearity present within the secondary and tertiary phases.

To derive a representative rate for the development of strains we fitted least squares lines in the secondary region. This extended in tensile tests in between 10-90\% of the complete lifetime of the samples and in compression and shear practically in the mid-life section of about $40-60 \%$. Of course in tension the $40-60 \%$ estimate was coincident to the $10-90 \%$ estimate as the linearity extended over the $10-90 \%$ range and so as a generic rule one may consider that all rates were calculated at a $40-60 \%$ mid-life range.

Fitting the linear regressions allows us to describe the behaviour by an 'intercept' strain value at the start of cycling and a 'rates of strain' given as the two slopes of $\dot{\epsilon}_{\mathrm{a}}$ and $\dot{\epsilon}_{\mathrm{p}}$. Further analysis is possible by then examining how the damage $\left(\dot{\epsilon}_{\mathrm{a}}\right)$ and plastic $\left(\dot{\epsilon}_{\mathrm{p}}\right)$ rates behave as a function of stress, age, loading mode or any other specimen characteristics.

Fig. $4 \mathrm{a} \& \mathrm{~b}$ show the behaviour of the strain rates versus nominal stress in the 3 loading modes. As strain rates varied by orders of magnitude (very much like the cycles to failure) logarithmic values for strain rates are used here and for the analysis that follows. Stress remained as is because the $\mathrm{R}^{2}$ values of strain rates vs. stress did not improve appreciably when $\log$ (stress) was used. 
In some cases, as seen in previous publications the variability of the data $\left(\mathrm{R}^{2}\right)$ caused by interindividual variation can be reduced if the strain rates are plotted versus normalised stress (stress/modulus). Table I summarises: (i) the relationship for strain rates vs. stress (eq.1-6) and normalised stress (eq.7-12) and (ii) for $\dot{\epsilon}_{\mathrm{a}}$ plotted against the plastic rate $\dot{\epsilon}_{\mathrm{p}}$ (Fig.5) for all the data collected here (eq.13-16). Normalised stress did reduce the variability for tension (eq. 7 and 10), but did not help in the cases for compression and shear. That may possibly be caused by errors in measuring the modulus accurately in these two modes, but we have included the relationships here for completeness of discussion.

The difference in the slopes and intercepts of the regressions were analysed ${ }^{21}$ and are shown in Table II. The statistics confirm one's visual impression: the slopes of the lines are in general the same, and the heights of the distributions about the common slope show only that the compression values are slightly below the tension and shear values. In shear the slope of the damage rate vs. stress was different than in tension and compression (Table II, no.1,2), while as far as plastic strain rates vs. stress (Table II, no.3,4) and plastic vs. elastic strain rates (Table II, no.5) are concerned the slopes against stress were equal for all 3 loading modes.

An analysis of covariance was performed to determine whether the relationships we examined different significantly between the various individuals. Plastic or elastic strain rate was the 'response' variable, and the five individuals (four in the case of shear) were the 'treatments' and 'stress' was a covariate. Table III shows that although there were some differences between the individuals (none in the case of shear) the level of 'stress' was of far greater importance in determining plastic or elastic strain rate. We also found that when the 'age' of the individuals was added as a second explanatory variable to the regressions relationships 1-6 of Table I it never achieved significance. This suggests that the relationship between stress and strain rate does not change uniformly (going one way) with age, and this suggestion was confirmed further by analysis of the residuals. The generic nature of these results certainly hints to a more general and rudimentary structure based mechanism as being the causal factor behind the damage related trends we report here.

\section{DISCUSSION}

The occurrence of non-linear and occasionally irreversible strains in bone has been reported early on by J.Currey ${ }^{22}$ as 'anelasticity', later on as 'nonelasticity' ${ }^{23}$, or 'viscoplasticity' ${ }^{24}$ and eventually as inelastic strain behaviour ${ }^{25}$. The inelastic behaviour was initially attributed to viscoelasticity, which was later on coupled with plasticity. It soon became clear however, that the nonlinear behaviour was reminiscent of damage accumulation in composite materials ${ }^{8}$. This was shown by two principal behavioural patterns; stiffness reductions and residual strains upon unloading. The observation of direct evidence of microcracking via optical and acoustic emission methods ${ }^{7}$ led eventually to the formulation of models depicting either perfect damage or viscoplastic damage situations ${ }^{25}$.

Early work focussed, naturally, on the stiffness reduction of the material bone in fatigue studies (which allow a continuous monitoring of stiffness loss) of human and animal cortical bone. The stiffness loss was described as a function of 'stress' or 'normalised stress', for bone tissue of varying internal architecture and different species ${ }^{11}$ and with a brief reference to some age effects ${ }^{10}$. However, considering the importance of a complete recording of the damage related behaviour of bone and the need to understand the mechanical behaviour around orthopaedic implants, it is surprising that the behaviour of bone in terms of the second most important behavioural pattern, namely the accumulation of residual strains upon unloading, has been generally overlooked till very recently ${ }^{13}$.

The present study produced novel information in three respects: (i) damage and strain accumulation has been recorded as a function of 'stress' and 'cycle number' for the 3 primary loading modes: tension, compression and shear; (ii) bone tissue material was made available to us from six different individuals spanning ages between 53 to 79 years old, which could illuminate age differences; (iii) 
there was enough material from each individual (both right and left femurs) to allow testing of paired samples and record fatigue strength and damage accumulation for tension, compression and shear within each donor and in between donors; (iv) the data collected in shear is also unique and was obtained via a recently implemented methodology 20 .

Samples were matched between right and left femora. A stratified random procedure was used, specimens being assigned to different stress levels according to their undamaged ('virgin') modulus of elasticity. This procedure ensured that there was no overrepresentation of low- or high-modulus specimens tested at low- or high-stresses. The only restriction in an otherwise randomised selection was the location of harvesting the shear specimens, which were taken slightly away from the middiaphysis section because they needed to be longer and transverse. This may have resulted in specimens, which were relatively less anisotropic, slightly more porous and more remodelled than at mid-diaphysis, but preliminary material analysis suggests that the difference in these material features were not in fact statistically different between the 3 groups of specimens for tension, compression and shear.

In order to summarise the present findings in a digestible form (also able to be implemented by FE analysts) we chose to treat and concentrate on strain rate patterns rather than strain magnitude values. The actual strain values: (i) developed in a curvilinear manner as a function of the cycle number as shown in Fig. 3 and for all 3 modes; (ii) the irreversible (plastic) strains were in magnitude a small fraction (30\%) of the total strains but larger than the damage strains in general. The 'plastic' strain rates were as a whole identical to the damage rates in compression (Fig. 5) and about $85 \%$ and $87 \%$ of the damage rates in shear and tension. One has to bear in mind that we are talking about strain rates, which describe a linear increase of either strain as a function of cycle number in fatigue. The practical significance of these findings is of course that it provides a characterisation of bone by 'coding' this very basic biomechanical data in the simplest possible manner and in a way that will allow it to be used in computer modelling and biomechanical analysis.

Even more interesting is the relationship shown in Fig. 5. The logarithms of the 'recoverable' and 'irrecoverable' strain rates are clearly tightly and almost linearly related. The power law relating them is (Table I): Plastic strain rate $\propto$ (Elastic strain rate) ${ }^{0.892}$. We are not interested here in predicting plastic strain rate from elastic strain rate, or vice versa, rather we are interested in the functional relationship between the two variables. The values are in $\operatorname{logs}$, the value of $\mathrm{R}^{2}$ is 0.856 , so $\mathrm{R}$ is 0.925 , and the power law for the functional relationships can be estimated from the slope of the reduced major axis. This is obtained by dividing the regression coefficient by the correlation coefficient ${ }^{27}$. This results in an estimate of $0.0892 / 0.925=0.964$; that is to say, the power law relationship is very close to unity, and so the log values of plastic strain rate and elastic strain rate are nearly proportional to each other.

The very generic nature of Fig.5 may have its basis in a more profound structural feature of bone and how it responds to damage. The fact that the relationship applies across 6 different individuals of varying ages, different internal bone architecture, cortical porosity, bone mineral status and so forth, points out that the causal factor of this behaviour is probably at the bone matrix level. There have been efforts to depict deformation phenomena at the ultrastructural level so as to account for damage observed of both in a diffuse form and as discrete microcracks.

Two such models are shown in fig.6. Fig.6a shows a typical single idealised microcrack at an oblique random angle to a uniaxial stress field as commonly seen in engineering mechanics formulations at a meso-mechanical level. In general, and regardless of the nature of the stress field, the crack is activated with forces on the fracture surfaces, which will in general be resolved normal to the surface (in tension this results in dilatational forces ' $d$ ') and in traction forces parallel to the faces of the crack ' $t$ '. When stress is relieved the traction forces work in the opposite direction, but the asperities of the surfaces result in the crack remaining open (activated) and give rise to residual strains such as those we saw here. The increase in crack length it is, this way, intrinsically linked to plastic/irrecoverable deformation very much in accordance with the data we have recorded here. This is a simple model that can explain many of the trends found in our results, and in those of 
others and may offer indirect, but nevertheless compelling evidence that the inelastic phenomena seen at bone matrix level can be understood on the basis of nucleation and growth of microcracks even when they resemble plasticity.

The second model is of a biophysical nature and derives from the ultrastructure of bone at the mineralised fubirlk level (fig.6b). The mineral apatite crystals nucleate at the hole zone of the quarter staggered collagen aggregate structure and they stretch in the overlap region nearby. Upon loading collagen experiences tensile and shear loading (red vectors), which at some threshold level may cause dissociation of the crystallites from the collagen matrix. That will have as a consequence a loss of structural integrity (loss in stiffness) and will result in exposed active calcium ions, which can be easily stained by stains such as basic fuch $\sin ^{17}$ and thus confirm and demonstrate the socalled 'diffuse' damage phenomenon. There is still a question mark of course with respect to this biophysical model in that it does not easily demonstrate and link plasticity with elastic degradation the way that the meso-mechanical model (a) does. However, both models help us conceptualise and grapple with the damage phenomena we have reported here.

Further investigations are required of course to establish the lesser influences of material level parameters (density, mineral content, condition of collagen) to the development and accumulation of both the elastic and plastic strains as seen here in fatigue. The influence of density, mineral, and other material constants has previously been examined with respect to the fatigue strength of bone, but not in terms of the development of damage and strain accumulation. Examination of some 'key' material parameters together with the present strain rate behaviour parameters may greatly influence our ability to understand the behaviour of bone around implants and in various other biomechanical applications in the future.

This study was supported by the EPSRC-UK (GR/M59167). The tests were carried out in the Biomechanics Laboratories of Cranfield University Postgraduate Medical School, Shrivenham, UK. The authors would like to thank those bereaved families who kindly donated tissues to be used for the benefit of others.

\section{References}

1. Kim D-G, Miller MA, Mann KA. A fatigue damage model for the cement-bone interface. J Biomech 2004; 3: 1505-1512.

2. Taylor M, Tanner KE, Freeman MAR, Yettram AL. 1995. Cancellous bone stresses surrounding the femoral component of a hip prosthesis an elastic-plastic finite element analysis. Med Eng Phys 1995; 17: 544-550.

3. Taylor M, Tanner KE. Fatigue failure of cancellous bone a possible cause of implant migration and loosening. J Bone Joint Surgery 1997; 79B: 181-182.

4. Berry DJ, Harmen WS, Cabanela ME, Morrey BF. Twenty-five-year survivorship of two thousand consecutive primary Charnley total hip replacements. J Bone Joint Surgery 2002; 84A: 171-177.

5. Maher SA, Prendergast PJ, Lyons CG. Measurement of the migration of a cemented hip prosthesis in an in vitro test. Clin Biomech 2001; 16: 307-314.

6. National Audit Office Report by the comptroller and auditor general. Hip replacements getting it right first time. HC417 Session, 1999/2000, 19th April 2000.

7. Zioupos P, Currey JD, Sedman A. An Examination of the Micromechanics of Failure of Bone and Antler by Acoustic-Emission Tests and Laser-Scanning-Confocal- Microscopy. Med Eng Phys 1994; 16: 203-212.

8. Carter DR, Hayes WC. Compact Bone Fatigue Damage-I. Residual Strength and Stiffness. J Biomech 1977; 10: 325-337. 
9. Fleck C, Eifler D. Deformation behaviour and damage accumulation of cortical bone specimens from the equine tibia under cyclic loading. J Biomech 2003; 36: 179-189.

10. Zioupos P, Wang XT, Currey JD. The Accumulation of fatigue microdamage in human cortical bone of two different ages in vitro. Clin Biomech 1996; 11: 365-375.

11. Choi K, Goldstein SA. A comparison of the fatigue behavior of human trabecular and cortical bone tissue. J Biomech 1992; 25: 1371-1381.

12. Haddock SM, Yeh OC, Mummaneni PV, Rosenberg WS, Keaveny TM. Similarity in the fatigue behavior of trabecular bone across site and species. J Biomech 2004; 37: 181-187.

13. Winwood K, Zioupos P, Cotton J, Taylor M. The development of 'plastic' strains during fatigue damage accumulation of ageing human cortical bone. Congress of the International Society of Biomechanics, Zurich, Switzerland, July 8-13th 2001.

14. Winwood K. An experimental investigation into the effects of fatigue on human cortical bone. PhD thesis. Department of Materials \& Medical Sciences, Cranfield University, 2003.

15. Cotton JR, Zioupos P, Winwood K, Taylor M. Analysis of creep strain during tensile fatigue of cortical bone. J Biomech 2003; 36: 943-949.

16. Cotton JR, Winwood K, Zioupos P, Taylor M. Damage rate is a predictor of fatigue life and creep strain rate in tensile fatigue of human cortical bone samples. J Biomech Eng 2005; 127: 213-219.

17. Burr DB, Martin RB. Calculating the probability that microcracks initiate resorption spaces. $\mathbf{J}$ Biomechanics 1993; 26:613-616.

18. O'Brien FJ, Taylor D, Dickson GR, Lee TC. Visualisation of three-dimensional microcracks in compact bone. J Anatomy 2000; 197:413-420.

19. Iosipescu N. New accurate procedure for single shear testing of metals. J Materials 1967; 18: 141-146.

20. Zioupos P, Casinos A, Winwood K. In-plane shear strength and fatigue damage properties of laminar bone. Proc. 13th European. Soc. Biomechanics Conference, Wroclaw Poland, Sept. 2002.

21. Snedecor GW, Cochran WG. Statistical methods. 7th Edition. Iowa State University Press, p.385, 1980.

22. Currey JD. Anelasticity in bone and echinoderm skeletons. J Exper Biology 1965; 43: 270292.

23. Bonfield W, Li CH. Anisotropy of nonelastic flow in bone. J Appl Physics 1967; 38: 24502455.

24. Fondrk MT, Bahniuk EH, Davy DT, Michaels C. Some viscoplastic characteristics of bovine and human cortical bone. J Biomech 1988; 21: 623-630.

25. Fondrk MT, Bahniuk EH, Davy DT. A damage model for nonlinear tensile behavior of cortical bone. J Biomech Eng 1999; 121: 533-541.

26. Fondrk MT, Bahniuk EH, Davy DT. Inelastic strain accumulation in cortical bone during rapid transient tensile loading. J Biomech Eng 1999; 121: 616-621.

27. Rayner JMV. 1985. Linear relations in biomechanics: The statistics of scaling functions. J Zoology (London) 1985; 206A: 415-439.

28. Jäger I, Fratzl P. Mineralized collagen fibrils: a mechanical model with a staggered arrangement of mineral particles. Biophysical J, 2000; 79:1737- 46. 


\section{TABLE I}

Linear regression relationships between strain rates, stress (MPa) and normalised stress (stress/modulus) of the data in Fig. 4 \& 5 .

\begin{tabular}{|c|c|c|c|c|}
\hline No. & Equation & $\mathrm{R}^{2}$ & $\mathrm{p}$ & $\begin{array}{l}\text { Loading } \\
\text { mode }\end{array}$ \\
\hline 1 & $\log \left(\dot{\varepsilon}_{a}\right)=-12.8+0.0949$ stress $(\mathrm{MPa})$ & 0.62 & $<0.001$ & $\mathrm{~T}$ \\
\hline 2 & $\log \left(\dot{\varepsilon}_{\mathrm{a}}\right)=-11.6+0.0657$ stress $(\mathrm{MPa})$ & 0.69 & $<0.001$ & C \\
\hline 3 & $\log \left(\dot{\varepsilon}_{\mathrm{a}}\right)=-9.48+0.1480$ stress $(\mathrm{MPa})$ & 0.24 & 0.004 & S \\
\hline 4 & $\log \left(\dot{\varepsilon}_{\mathrm{p}}\right)=-11.7+0.0824$ stress $(\mathrm{MPa})$ & 0.54 & $<0.001$ & $\mathrm{~T}$ \\
\hline 5 & $\log \left(\dot{\varepsilon}_{\mathrm{p}}\right)=-11.7+0.0676$ stress $(\mathrm{MPa})$ & 0.60 & $<0.001$ & C \\
\hline 6 & $\log \left(\dot{\varepsilon}_{\mathrm{p}}\right)=-8.70+0.127$ stress $(\mathrm{MPa})$ & 0.23 & 0.005 & $S$ \\
\hline 7 & $\log \left(\dot{\varepsilon}_{a}\right)=-11.8+1093$ normalised stress & 0.64 & $<0.001$ & $\mathrm{~T}$ \\
\hline 8 & $\log \left(\dot{\varepsilon}_{\mathrm{a}}\right)=-11.1+761$ normalised stress & 0.50 & $<0.001$ & C \\
\hline 9 & $\log \left(\dot{\varepsilon}_{\mathrm{a}}\right)=-6.36+23.2$ normalised stress & 0.02 & $0.463^{a}$ & S \\
\hline 10 & $\log \left(\dot{\varepsilon}_{p}\right)=-10.9+978$ normalised stress & 0.59 & $<0.001$ & $\mathrm{~T}$ \\
\hline 11 & $\log \left(\dot{\varepsilon}_{p}\right)=-11.3+787$ normalised stress & 0.44 & $<0.001$ & C \\
\hline 12 & $\log \left(\dot{\varepsilon}_{p}\right)=-6.21+34.7$ normalised stress & 0.05 & 0.214 a & S \\
\hline 13 & $\log \left(\dot{\varepsilon}_{p}\right)=-0.543+0.872 \log \left(\dot{\varepsilon}_{a}\right)$ & 0.88 & $<0.001$ & $\mathrm{~T}$ \\
\hline 14 & $\log \left(\dot{\varepsilon}_{p}\right)=-0.036+0.997 \log \left(\dot{\varepsilon}_{a}\right)$ & 0.82 & $<0.001$ & C \\
\hline 15 & $\log \left(\dot{\varepsilon}_{\mathrm{p}}\right)=-0.608+0.850 \log \left(\dot{\varepsilon}_{\mathrm{a}}\right)$ & 0.91 & $<0.001$ & S \\
\hline 16 & $\log \left(\dot{\varepsilon}_{p}\right)=-0.497+0.892 \log \left(\dot{\varepsilon}_{a}\right)$ & 0.86 & $<0.001$ & All \\
\hline
\end{tabular}

a insignificant at $\mathrm{p}=0.05$

TABLE II

Analysis of the distributions shown in Fig. 4a,b \& Fig. 5.

\begin{tabular}{|c|c|c|c|c|}
\hline Comparison & $\begin{array}{c}\text { Shear } \\
\text { included? }\end{array}$ & Slopes different? & Heights different? & No. \\
\hline \multirow{2}{*}{ Elastic strain rate vs. stress } & Yes & Yes, $p \leq 0.05$ & $\begin{array}{c}\text { Yes, } \mathrm{p}<<0.001 \\
\text { (S higher, C lower) }\end{array}$ & 1 \\
\hline & No & No & $\begin{array}{c}\text { Yes, } p<<0.001 \\
\quad(C \text { lower })\end{array}$ & 2 \\
\hline \multirow{2}{*}{ Plastic strain rate vs. stress } & Yes & No & $\begin{array}{c}\text { Yes, } \mathrm{p}<<0.001 \\
\text { (S higher, C lower) }\end{array}$ & 3 \\
\hline & No & No & $\begin{array}{c}\text { Yes, } p<<0.001 \\
\quad(C \text { lower })\end{array}$ & 4 \\
\hline $\begin{array}{l}\text { Plastic strain rate vs. Elastic } \\
\text { strain rate }\end{array}$ & Yes & No & $\begin{array}{l}\text { Yes, } p=0.01 \\
(C \text { lower?) }\end{array}$ & 5 \\
\hline
\end{tabular}

Comparison of slopes and heights [20]; considered to show a difference at $\mathrm{p} \leq 0.05$. 
TABLE III

ANCOVA for the effect of the stress and the individual, on plastic or elastic strain rate.

\begin{tabular}{llllll}
\hline Loading mode & Strain rate & $\begin{array}{l}\text { Individual } \\
\text { F, d.f }\end{array}$ & $\begin{array}{l}\text { Individual } \\
p\end{array}$ & $\begin{array}{l}\text { Stress } \\
F, \text { d.f }\end{array}$ & $\begin{array}{l}\text { Stress } \\
p\end{array}$ \\
\hline Tension & Plastic & $3.25,5,40$ & 0.015 & $75.87,1,40$ & $<<0.001$ \\
Tension & Elastic & $7.08,5,40$ & $<<0.001$ & $141.62,1,40$ & $<<0.001$ \\
Compression & Plastic & $3.03,5,40$ & 0.022 & $90.49,1,37$ & $<<0.001$ \\
Compression & Elastic & $3.63,5,37$ & 0.009 & $140.37,1,37$ & $<<0.001$ \\
Shear & Plastic & $1.22,4,27$ & 0.326 & $11.54,1,27$ & 0.002 \\
Shear & Elastic & $1.50,4,27$ & 0.231 & $14.14,1,27$ & 0.001 \\
\hline
\end{tabular}

\section{FIGURE LEGENDS}

Figure 1 Site and geometry of samples prepared from human femora. Tensile and compressive sample were longitudinally oriented (with the compressive samples being shorter and stubbier than the tensile ones to avoid buckling), shear samples were prepared in the Iosipescu design in order to examine shear properties in the in-between the osteons direction.

Figure 2 Stress (nominal) / strain (engineering) curves at the start $(\mathrm{N}=1,2)$ and at failure in a compression specimen of cortical bone $(F 54 \# 19$, cycles to failure $=259$, stress $=110 \mathrm{MPa})$. The translation in the strain axis (the strains shown here apply to the penultimate cycle $\mathrm{N}_{\mathrm{f}}-1$ ) is the irrecoverable strain $\left(\epsilon_{\mathrm{p}}\right)$. The increase in the elastic $\left(\epsilon_{\mathrm{a}}\right)$ strain amplitude is a result of the incipient damage and the rate of its increase $\dot{\epsilon}_{\mathrm{a}}$ is analogous to the rate of damage. Total strain is simply $\epsilon_{\mathrm{T}}=\epsilon_{\mathrm{a}}+\epsilon_{\mathrm{p}}$.

Figure 3 Trends for total strain $\left(\epsilon_{T}\right)$ and plastic strain $\left(\epsilon_{p}\right)$ for 2 specimens tested in (a) tension (F54\#5, stress=81 MPa, $\mathrm{N}_{\mathrm{f}}=556, \mathrm{E}=14.9 \mathrm{GPa}$ ); and (b) compression (F54\#19, stress=110 MPa, $\mathrm{N}_{\mathrm{f}}=259, \mathrm{E}=14 \mathrm{GPa}$ ) from the $54 \mathrm{yr}$ old female showing how the representative elastic (damage) and plastic strain rates were calculated.

Figure 4 The behaviour (a) of the damage rate $\left(\dot{\epsilon}_{\mathrm{a}}\right)$ and (b) of the plastic crate $\left(\dot{\epsilon}_{\mathrm{p}}\right)$ as a function of stress for the 3 loading modes.

Figure 5 Elastic strain rate $\left(\dot{\epsilon}_{\mathrm{a}}\right.$, recoverable strain) versus the plastic strain rate ( $\dot{\epsilon}_{\mathrm{p}}$, irrecoverable strain) in human cortical bone during tensile, compressive, and shear cyclic fatigue loading.

Figure 6 Structural models as a driving factors of the phenomena seen here (a) meso-mechanical model of a single microcrack, depicted at a random oblique angle of orientation $(\theta)$ to a uniaxial stress field (S); (b) biophysical model (modified ${ }^{28}$ ) of mineralised collagen fibrils impregnated with apatite crystals (blue) and experiencing tension and shear (red vectors) upon stretching. 
Figure 1

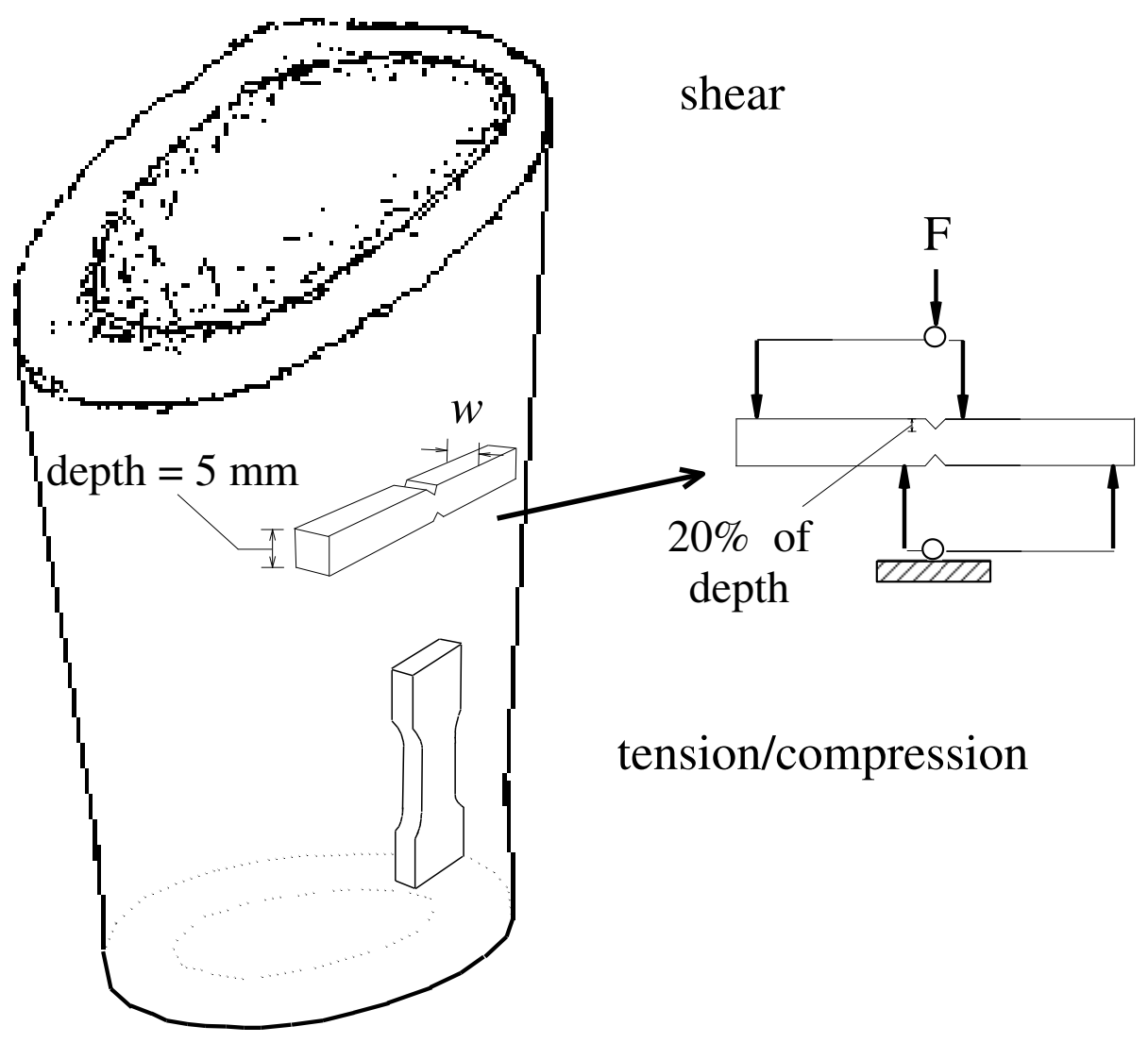


Figure 2

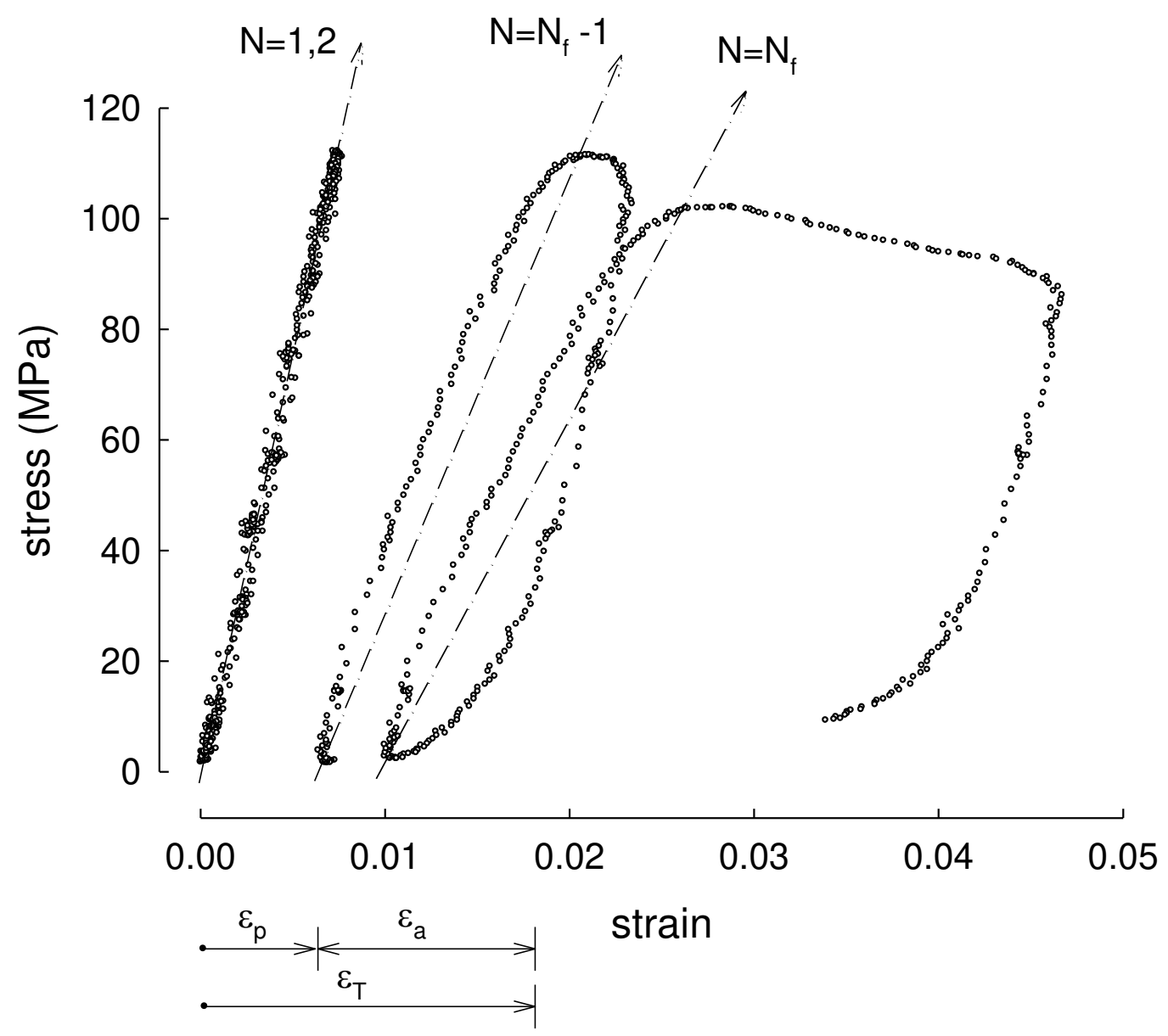


Figure 3
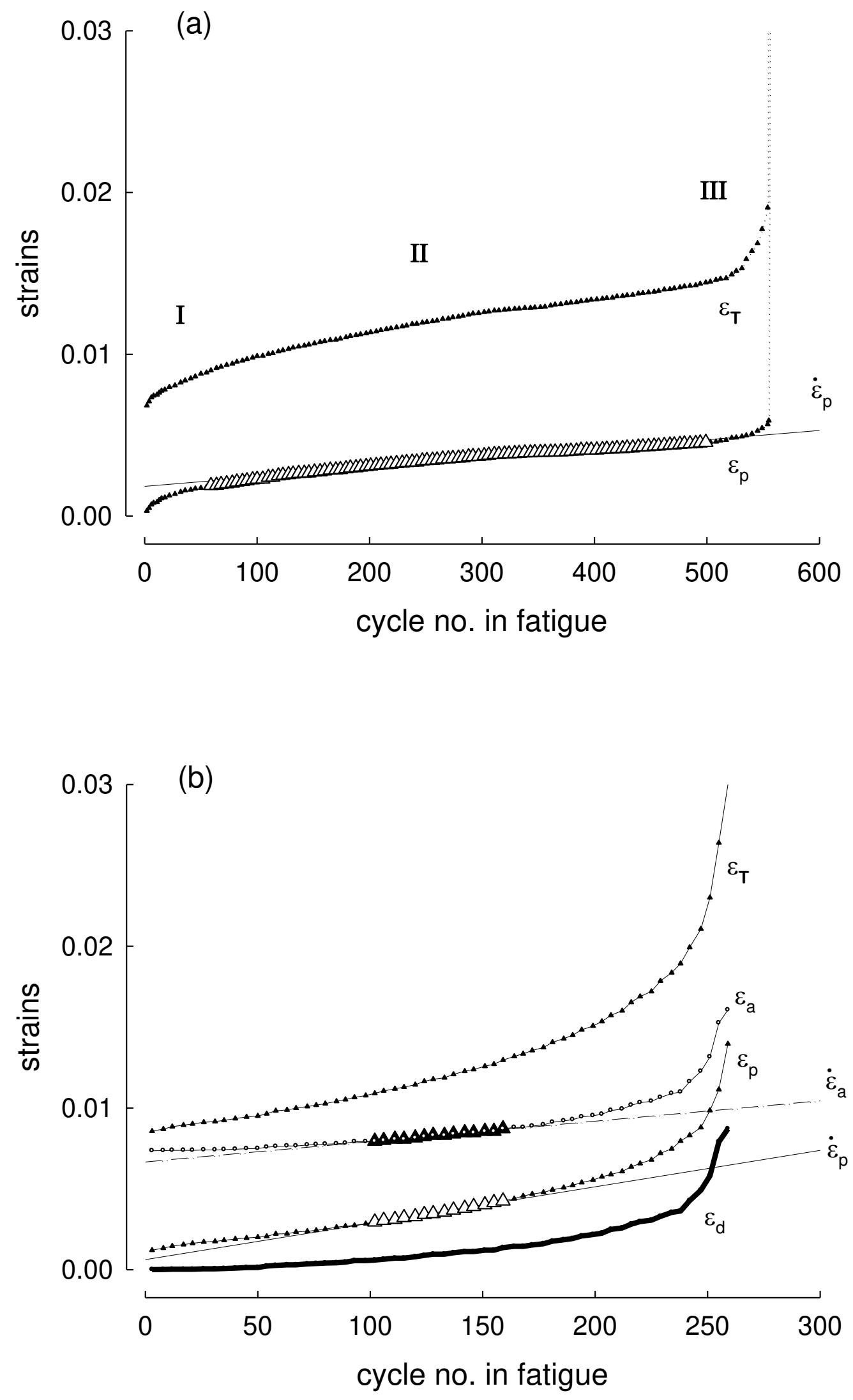
Figure 4
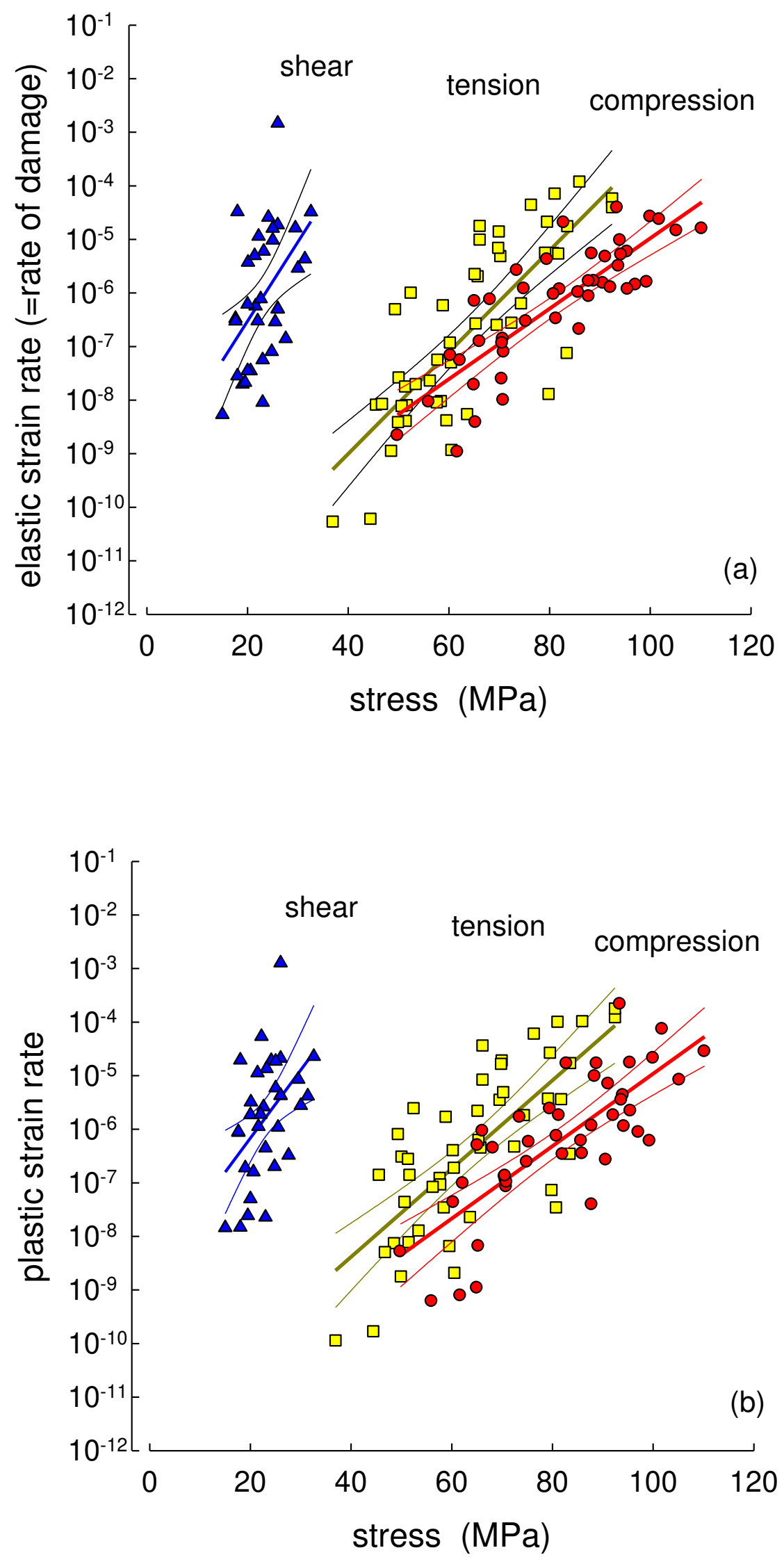
Figure 5

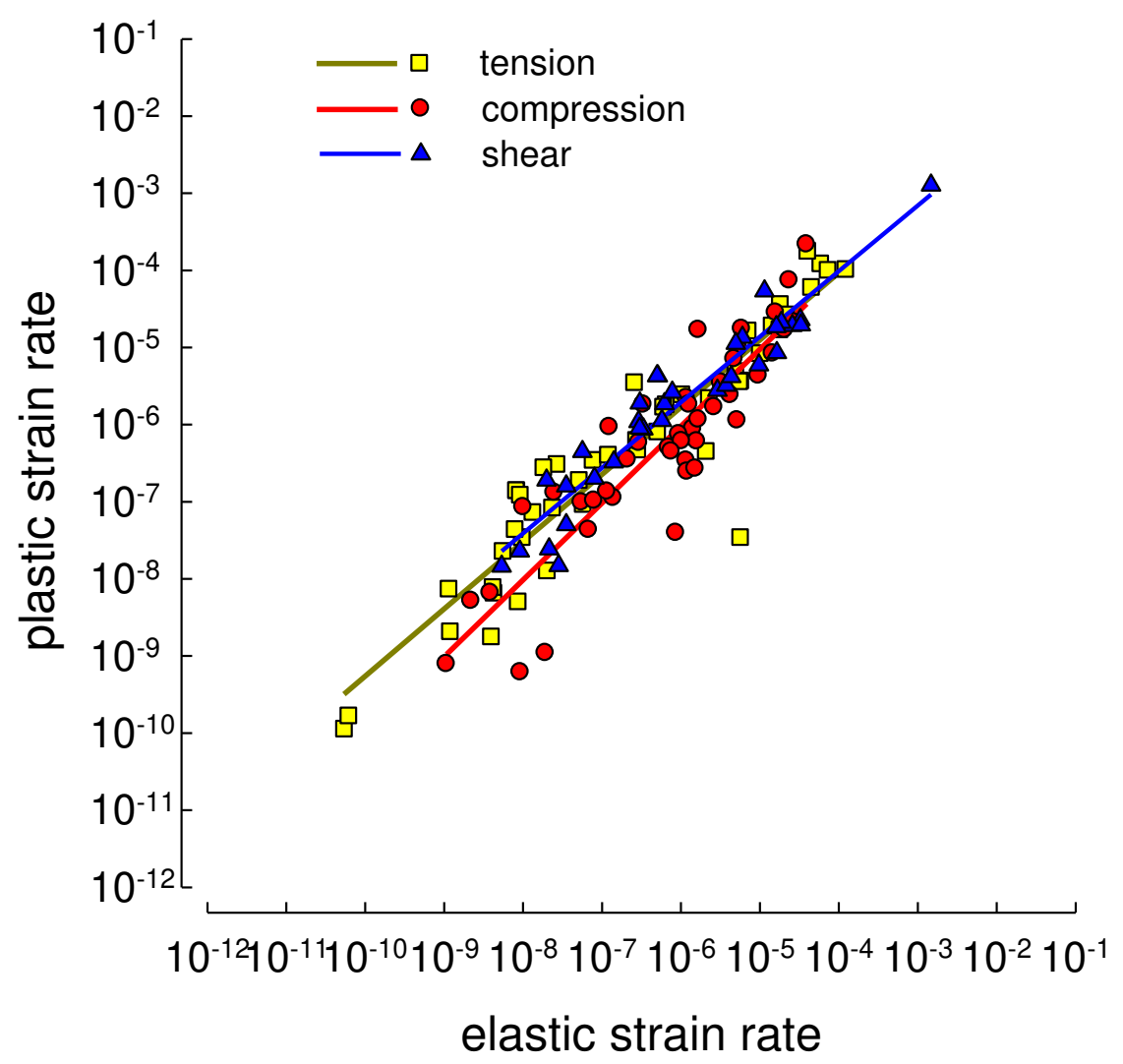


Figure 6

(a)

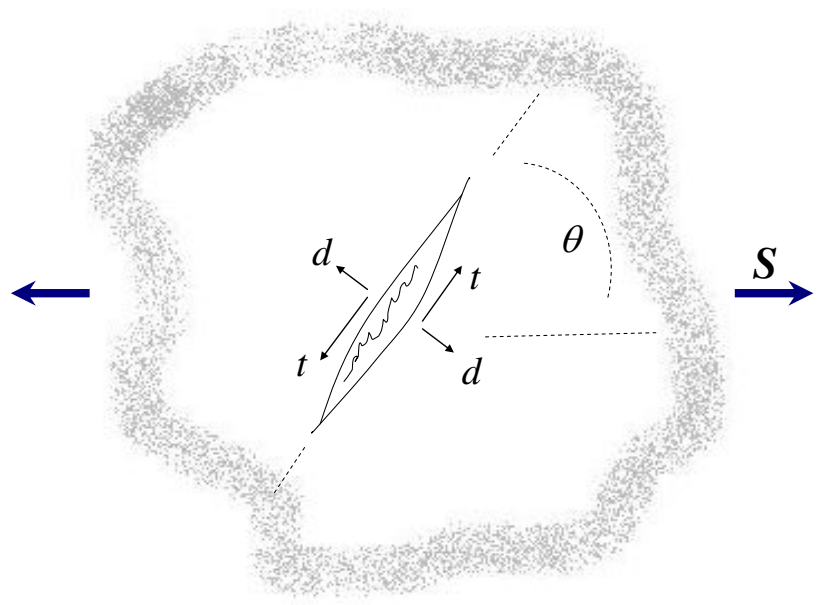

(b)

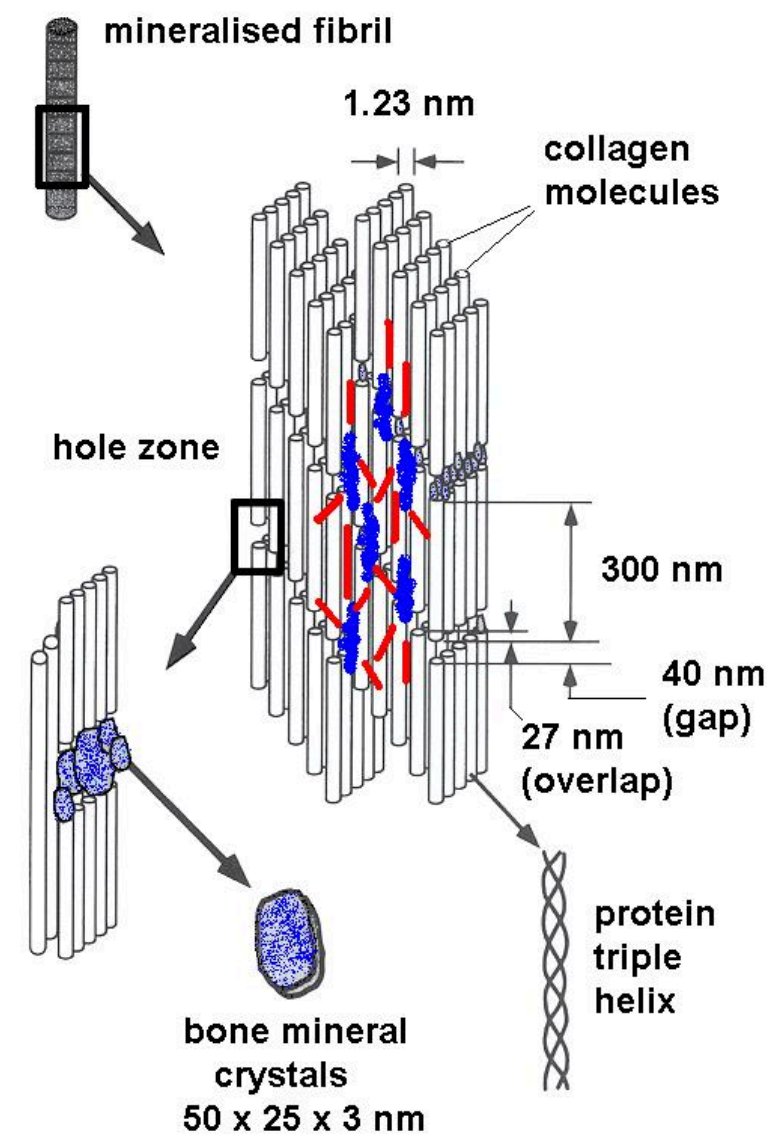

